\title{
A IDENTIDADE PROFISSIONAL INSTITUCIONAL Atualidade da pesquisa em serviço social
}

Telmo H. Caria

Escola de Ciências Humanas e Sociais da Universidade de Trás-os-Montes e Alto Douro

Paula Sousa

Escola de Ciências Humanas e Sociais da Universidade de Trás-os-Montes e Alto Douro

José Luís Almeida

Escola de Ciências Humanas e Sociais da Universidade de Trás-os-Montes e Alto Douro

Resumo Este artigo tem como principal objetivo questionar o modo como se analisa a identidade profissional em serviço social. Apresenta-se uma revisão da literatura sociológica, com forte cunho sócio-histórico, sobre a teoria social da identidade e dela se retiram consequências e hipóteses sobre o lugar central que em Portugal as entidades de educação formal superior dos assistentes sociais têm ocupado na construção social da identidade institucional desta profissão. Com base nesta revisão, chega-se a uma definição operacional de consciência identitária institucional dos assistentes sociais e fazem-se várias considerações metodológicas sobre o uso de um questionário para o estudo deste tema.

Palavras-chave: identidade profissional, serviço social, consciência institucional identitária, formas sociais identitárias.

Abstract This article has as main objective to question how the professional identity in Social Work is analyzed. It presents a review of the sociological literature, with a strong socio-historical vision, on the social theory of identity and, from it, draws consequences and hypotheses about the central place that higher formal education of social workers have occupied in the social construction identity of this profession. Based on this review, we arrive at an operational definition of institutional identity consciousness of social workers and make several methodological considerations about the use of a questionnaire to study this issue.

Keywords: professional identity, social work, identity forms, institutional identity awareness, social identity formats.

Résumé Cet article vise à remettre en question la façon dont nous analysons l'identité professionnelle dans le travail social. Il présente une revue de la littérature sociologique, avec un fort caractère socio-historique, sur la théorie de l'identité sociale et prend sa retraite des conséquences et des hypothèses sur le lieu central que, au Portugal, les entités de l'enseignement supérieur formel des assistants sociaux ont occupé dans la construction sociale de l'identité institutionnelle de cette profession. Sur la base de cet examen, nous arrivons à une définition opérationnelle de la conscience de l'identité institutionnelle des assistants sociaux et composons diverses considérations méthodologiques sur l'utilisation d'un questionnaire pour l'étude de ce sujet.

Mots-clés : identité professionnelle, assistants sociaux, conscience de l'identité institutionnelle, formes identitaires sociales.

Resumen Este artículo tiene como principal objetivo cuestionar el modo como se analiza la identidad profesional en Servicio Social. Se presenta una revisión de la literatura sociológica, con fuerte orientación socio-histórica, sobre la teoría social de la identidad y de ella se extraen consecuencias e hipótesis sobre el lugar central que en Portugal los organismos de educación superior de los trabajadores sociales han ocupado en la construcción social de la identidad institucional de esta profesión. Con base en esta revisión, se alcanza a una definición operacional de consciencia identitaria institucional de los trabajadores sociales y se llevan a cabo varias consideraciones metodológicas sobre el uso de un cuestionario para el estudio de este tema.

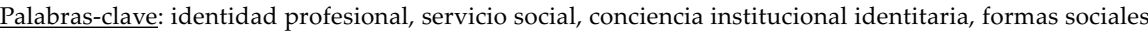
identitarias.

SOCIOLOGIA, PROBLEMAS E PRÁTICAS, n.․5, 2017, pp. 149-165. DOI: 10.7458/SPP2017852240 


\section{Introdução}

O conceito de identidade social tem tido, ao longo da história das ciências sociais, usos muito diversos e plurais, muito marcados pelas diversas tradições históricas e disciplinares e consequente fragmentação da especialização científica, sendo, por isso, um constructo teórico pouco consolidado que se presta a diversas confusões teórico-operacionais (Monteiro, Lima e Vala, 1999). Obviamente quando este conceito é aplicado, como faremos neste artigo, relativamente a uma atividade laboral no âmbito de uma profissão - o serviço social - inevitavelmente as conceptualizações existentes sobre a identidade profissional dos assistentes sociais se revelam muito dispersas e plurais, ainda que também sempre associadas a uma historicidade do conceito que convoca as mudanças da sociedade como contorno desta temática (Roda e Fonseca, 2011).

Abordar o tema da identidade profissional dos assistentes sociais em Portugal é pertinente e atual, pois estes profissionais, nos últimos anos e fruto da emergência de novas profissões sociais, estão a enfrentar um dos maiores desafios em termos da sua profissionalização, ainda em vias de consolidação e institucionalização. Este desafio é dificultado por uma alegada crise contemporânea na identidade do serviço social a nível global (Canavan, 2009), que se manifesta pela ausência de uma identidade profissional robusta e segura. Esta ideia é também referida por Asquith, Clark e Waterhouse, ao argumentarem que a alegada crise que o serviço social enfrenta é sobretudo uma crise de identidade profissional e, apoiando-se numa ampla revisão da literatura, declararem haver "uma necessidade urgente para o serviço social de clarificar a sua identidade profissional e a sua distinção comparativamente a outras profissões" (Asquith, Clark e Waterhouse, 2005: 4). Neste âmbito, Stephen Webb refere que a investigação sobre a identidade profissional em serviço social apesar de estar atualmente na ordem do dia, até ao momento não tem uma conceptualização estável, e empiricamente não se tem ido muito longe (Webb, 2015). Citando Malcom Payne, acrescenta que se trata de um tema sobre o qual se sabe pouco em serviço social, porque uma parte significativa da investigação nesta área de conhecimento tem reduzido o tema da identidade dos assistentes sociais ao desempenho de papéis definidos pelas políticas, mais do que às conceções mais amplas sobre o potencial desses papéis (Payne, 2006).

Do ponto de vista sociológico, fruto das transformações históricas da atual sociedade, o conceito contém uma dupla tensão teórica, nem sempre bem resolvida, julgamos, pelos vários autores e correntes de pensamento. Assim, como veremos ao longo do artigo, o conceito de identidade social inscreve uma tensão entre o individual e o coletivo e, ao mesmo tempo, uma tensão entre a identidade como relação de pertença social (com forte conteúdo de natureza emocional-prática) e a identidade como relação de diferenciação-distinção social (com forte conteúdo de natureza consciente e autorreflexiva). Duas forças aparentemente contraditórias de sentido inverso: a força centrípeta de pertença a um "nós" com o "outro" e a força centrífuga de diferenciação do "nós" para com o "outro" (Mendes, 2001).

Apresentamos neste artigo uma revisão da literatura sociológica sobre o conceito de identidade profissional, situando-o por relação aos contextos de 
identificação social da profissão, optando assim por dar maior relevância analítica às forças centrífugas da identidade profissional (uma identidade social coletiva atribuída pelos outros e para os outros), e não tanto às forças centrípetas, a fim de mais facilmente não confundir este conceito com o de identidade pessoal de cada profissional (identidade-para-si) ou com o de cultura-identidade de grupo (identidade de pertença coletiva). Como explicaremos ao longo do artigo, entendemos a identidade profissional do serviço social como a identificação social que se expressa e manifesta no âmbito do contexto de trabalho profissional dos assistentes sociais, ${ }^{1}$ tendo por referência as categorias sociais e de conhecimento que foram institucionalizadas e veiculadas pelas escolas de educação formal da profissão.

Para este efeito faremos uma reinterpretação teórica das contribuições sócio-históricas de Claude Dubar (2000) sobre o tema, por via do conceito de formas sociais identitárias. A revisão da literatura apresentada pretende também fundamentar um propósito instrumental: enquadrar e operacionalizar um estudo por questionário sobre a consciência identitária institucional em serviço social, entretanto já realizado. Face ao espaço disponível para este artigo, a metodologia, os resultados e as conclusões do estudo empírico não poderão ser incluídos. No entanto, daremos, no final, uma definição operacional do conceito, a partir de algumas considerações metodológicas sobre o ajustamento entre a pesquisa deste tema e o uso de um inquérito por questionário.

\section{O conceito moderno de identidade social}

Para melhor dar conta dos condicionalismos históricos e sociais que têm determinado o uso do conceito de identidade social, Claude Dubar (2000) desenvolve a noção de formas identitárias. Refere este autor que a identidade social na sua primeira forma histórica se confunde com o conceito de comunidade, acrescentando que nestas condições históricas particulares tende a haver uma grande fusão entre o individual e o coletivo, associado a um forte sentimento de pertença dos indivíduos aos grupos sociais de origem e de socialização primária (e, ao mesmo tempo, a um forte sentimento de estranheza face aos territórios e às categorizações que definem outros grupos sociais). Onde, portanto, a identidade social é assumida como óbvia e garantida, não chegando a ser objeto (da autorreflexão) da consciência dos indivíduos sobre si próprios (Giddens, 1994 [1991]).

É pensando na existência, extensão e sobrevivência ao longo da história da humanidade destes quadros comunitários de relações sociais (desta forma identitária) que Pierre Bourdieu (1972) desenvolve o conceito de habitus, de modo a salientar a tese de que estamos perante uma identidade histórica, incorporada, prático-cultural e em grande medida inconsciente - porque operando através de esquemas incorporados de perceção, apreciação e antecipação da vida social (Caria, 2002) - com uma

1 Na linha do debate que tem ocorrido nas últimas três décadas no âmbito da sociologia das profissões, conceptualizamos o serviço social como um trabalho profissional (Caria e Pereira, 2016), baseado em conhecimento formal e científico (Freidson, 1994; Champy, 2011). 
natureza simultaneamente simbólico-estrutural e estruturante de toda a prática social, sem dissociação entre ação individual e coletiva (Kaufmann, 2004).

No quadro de dissolução das formas identitárias comunitárias, Stuart Hall (2002 [1992]) refere o surgimento da identidade social moderna que, na linha de uma conceção iluminista do sujeito, faz surgir a oposição entre o individual-interno e o social-externo ao sujeito, na medida em que a estabilidade, a durabilidade e a continuidade do quadro de interações comunitárias, tradicionais e monoculturais, de origem pré-moderna, tende, progressivamente, a soçobrar com a emergência da sociedade capitalista industrial. Segundo este autor, como efeito das mudanças modernizadoras da sociedade, o conceito de identidade passa a ter uma conotação de conformidade e/ou de resistência individual à pressão e controlo social que os grupos primários de origem e pertença exercem sobre cada um dos seus membros. Passa a ter uma conotação de cariz oposto à noção de comunidade-identidade grupal, dando a cada indivíduo a possibilidade de desenvolver uma forte consciência pessoal e discursiva de diferenciação face à comunidade de pertença que o integra.

É nesta aceção iluminista que se corre o risco de passar a analisar em separado (e a confundir) a identidade pessoal e, por extensão, a identidade pessoal de cada assistente social com a identidade social e, por extensão, a identidade profissional do serviço social, dando à análise uma orientação essencialmente psicológica: um núcleo interno e consistente de organização identitário-psicológica (identidade pessoal) a que depois de juntariam conteúdos e categorias de identificação social, mais ou menos constrangedores e/ou qualificadores das pertenças sociais e coletivas do self. Nesta conceção psicologista esquece-se que o conceito de identidade contém sempre (de modo emergente) uma hipótese geral sobre a existência de uma ordem interacional na vida social, que nunca é unilateral (nem é específica das sociedades capitalistas modernas): (o que penso de mim) o que pensamos de nós nunca é independente do que (penso do outro) pensamos dos outros e o que os outros pensam de nós (pensam de mim) nunca é independente (do que eu) do que nós (penso do outro) pensamos dos outros (Jenkins, 2000).

É esta dinâmica que se procura apresentar na figura 1, por via das transições ocorridas entre o self e o outro, resultantes do cruzamento e conjugação das dimensões $\mathrm{A}, \mathrm{B}$ e $\mathrm{C}$ de construção identitário-profissional: as modalidades identitárias $\mathrm{AC}$ e BC, permitem considerar que os processos sociais de construção das identidades sociais contêm sempre duas componentes (Jenkins, 2000; Madureira-Pinto, 1991; Dubar, 1996): a identidade-para-si (também conceptualizada como autoidentificação, relação interna de pertença a grupos, identização, etc.) e a identidade-para-os-outros (também conceptualizada como categorização social da identidade, relação externa de identificação para com outros, identificação social, etc.). No entanto, sem prejuízo de se contemplar as duas componentes da construção das identidades sociais e profissionais, pode-se desenvolver - como faz Clara Santos (2005) quando aborda a identidade profissional dos assistentes sociais em Portugal - uma análise mais centrada nas forças identitárias centrípetas (modalidade AC), da identidade-para-si, na qual a construção identitária pessoal tem especial relevância dadas as conotações privadas, introspetivas e íntimas que lhe estão mais associadas por via das noções psicossociais de autoavaliação, de autoconceito e de 


\begin{tabular}{|c|c|c|c|c|}
\hline & $\begin{array}{c}\text { Dimensão C: } \\
\text { IDENTIDADE REAL }\end{array}$ & $\begin{array}{c}\text { TRANSIÇÕES } \\
\text { (grau de separação entre } \\
\text { o passado e o futuro) }\end{array}$ & $\begin{array}{l}\text { Dimensão D: } \\
\text { IDENTIDADE } \\
\text { IMAGINADA }\end{array}$ & \\
\hline $\begin{array}{c}\text { Dimensão A: } \\
\text { IDENTIDADE PARA SI }\end{array}$ & $\begin{array}{c}\text { Modalidade AC } \\
\text { Identidade herdada } \\
\text { e interiorizada } \\
\text { (quem sou para mim?) }\end{array}$ & $\begin{array}{c}\text { Atualização do herdado } \\
\text { face às mudanças do } \\
\text { presente. } \\
\text { Trajetórias sociais e } \\
\text { biografias multiculturais. }\end{array}$ & $\begin{array}{c}\text { Modalidade AD } \\
\text { Identidade } \\
\text { ambicionada } \\
\text { (quem quero passar } \\
\text { a ser para os outros?) }\end{array}$ & \multirow{3}{*}{$\begin{array}{c}\text { IDENTIDADE } \\
\qquad \\
\downarrow \\
\downarrow \\
\downarrow \\
\downarrow \\
\downarrow \\
\downarrow \\
\text { PODERES } \\
\downarrow\end{array}$} \\
\hline $\begin{array}{c}\text { TRANSIÇÕES } \\
\text { (grau de } \\
\text { [des]continuidade } \\
\text { entre si e os outros) }\end{array}$ & $\begin{array}{l}\text { Expectativas, } \\
\text { assimetrias e } \\
\text { estranhamentos } \\
\text { relacionais. } \\
\text { Constrangimentos } \\
\text { sociais e } \\
\text { institucionais. } \\
\text { Experiência social } \\
\text { acumulada de } \\
\text { diferenciação, } \\
\text { adaptação e } \\
\text { mudança sociais. }\end{array}$ & $\begin{array}{l}\text { CONTINUIDADES } \\
\text { E ENCAIXES? }\end{array}$ & $\begin{array}{l}\text { Associativismo e } \\
\text { ideologia profissional. }\end{array}$ & \\
\hline \multirow[t]{2}{*}{$\begin{array}{l}\text { Dimensão B: } \\
\text { IDENTIDADE PARA } \\
\text { OS OUTROS }\end{array}$} & $\begin{array}{c}\text { Modalidade BC } \\
\text { Identidade atribuída } \\
\text { (o que os outros } \\
\text { esperam que eu } \\
\text { possa ser?) }\end{array}$ & $\begin{array}{c}\text { Políticas sociais, } \\
\text { mercado de trabalho e } \\
\text { organizações de trabalho } \\
\text { social. } \\
\text { Poder, disputas e } \\
\text { competição entre grupos } \\
\text { profissionais. }\end{array}$ & $\begin{array}{c}\text { Modalidade BD } \\
\text { Identidade legítima } \\
\text { (o que os outros } \\
\text { esperam que eu deva } \\
\text { ser?) }\end{array}$ & \\
\hline & \multicolumn{3}{|c|}{ IDENTIDADE $\rightarrow \rightarrow \rightarrow \rightarrow \rightarrow \rightarrow \rightarrow \rightarrow$ PROJETO $\rightarrow$} & $\begin{array}{c}\text { Projeto } \\
\text { de poder } \\
\text { profissional? }\end{array}$ \\
\hline
\end{tabular}

Figura 1 Dinâmica das modalidades de construção da identidade profissional nos processos de socialização Fonte: autoria de Telmo H. Caria, inspirado na teoria sociológica da socialização e da identidade profissional de Claude Dubar (1997 [1991]).

autoconhecimento do self. Ou, inversamente, como pretendemos neste artigo e no estudo empírico que se lhe seguiu, poder-se-á desenvolver uma análise mais centrada nas forças identitárias centrífugas (modalidade BC), da identificação-para-os-outros, na qual se salienta, preferencialmente, a consciência individual (dos assistentes sociais) sobre as categorizações e atributos sociais que podem definir a identidade da profissão e, implicitamente, a diferenciação face a outros grupos profissionais: a consciência identitária profissional.

Admitimos, na linha de argumentação crítica de Jean-Claude Kaufmann (2004), que esta definição da construção identitária socioprofissional é uma resposta limitada da sociologia à redução psicológico-essencialista do indivíduo, e que 
deste modo a identidade social se reduz a ser sinónimo de uma consciência individual da vida socioprofissional, isto é, ser apenas uma subjetivação dos processos de categorização social que estão presentes na socialização aceitando-se, implicitamente, algum atomismo social. Mas esta limitação sociológica é bem compreensível, porque é justamente, como veremos de seguida, consequência da teorização que a sociologia foi capaz de fazer da forma típica identitária do capitalismo industrial.

\section{A identidade social institucional}

Do exposto pensamos que terá ficado claro que a forma comunitária de manifestação da identidade profissional não tem relevância para o serviço social na atualidade: a aprendizagem e socialização (secundária) nesta profissão não ocorre no quadro (nem no prolongamento) de relações sociais comunitárias de socialização primária, nem no quadro de um modelo de aprendizagem social de cariz monocultural, no qual as trajetórias sociais do grupo social de pertença se confundiriam com os grupos sociais de referência. Portanto, a identidade profissional dos assistentes sociais não poderá ser concebida como a consciência individual de um qualquer habitus da profissão que distanciaria (caso existisse) cada profissional das relações sociais comunitárias dos pares. No entanto, não excluímos a possibilidade de poderem existir culturas profissionais em serviço social, na medida em que uma parte significativa da aprendizagem da profissão se pode fazer de modo prático, experiencial e intersubjetivo entre pares em organizações de trabalho (Sousa, 2014). E na medida em que os assistentes sociais se reconhecem entre si como partilhando uma prática, um processo de trabalho e uma linguagem comuns, que tem por referência uma atividade social categorizada como sendo uma profissão específica (ou um conjunto de categorizações sociais agregadas debaixo de uma mesma definição funcional) (Sainsaulieu, 1977; Brown, Kirpal e Rauner, 2007; Caria, 2005, 2009).

Esta cultura profissional não poderá ser considerada como uma cultura comunitária, porque ocorre no âmbito de uma socialização secundária em organizações de trabalho de prestação de serviços sociais e ocorre em contextos multiculturais de interação social assimétrica, e porque ocorre depois de uma educação formal superior prolongada, isto é, trata-se de uma aprendizagem profissional que, ainda que se faça com pares, está subordinada ao funcionamento ordenado e ordeiro de instituições sociais de trabalho e conhecimento (e suas recontextualizações verticais e conexões horizontais, Caria, 2008, 2014) e não subordinada a comunidades interpessoais de saber local baseadas na memória oral dos mais velhos, como tradicionalmente acontece nas formas identitárias comunitárias.

Neste âmbito, as culturas profissionais institucionais (não comunitárias) só podem desenvolver-se enquanto identidades sociais modernas da sociedade industrial, referenciadas por Claude Dubar (2000) como uma forma identitária, nova e específica do mundo moderno e capitalista: a forma identitária institucional-estatutária. Neste novo quadro de relações sociais, a consciência identitária individual já não é vista como um 
possível elemento de perturbação da identidade social de pertença dos indivíduos, dado que se assume como necessário à sociedade capitalista desenvolver um elevado grau de especialização e diferenciação funcional (campos sociais e simbólicos cada vez mais dissociados e autónomos), fazendo com que ao longo da vida os indivíduos possam desempenhar diferentes papéis sociais conforme as trajetórias sociais que vão experienciando.

$\mathrm{Na}$ forma identitária institucional o essencial da estabilidade, durabilidade e continuidade das relações sociais (o essencial dos processos de reprodução social) passa a depender, principalmente, de um sistema de papéis e estatutos sociais, de grupos de referência e de processos de socialização secundária no quadro de relações sociais desiguais e multiculturais, isto é, a identidade social passa a confundir-se com as posições sociais que os indivíduos ocupam nas instituições da sociedade burocrática e industrial e com as representações sociais que têm dessas posições nos vários campos sociais e simbólicos da vida social. Por via desta forma, a identidade profissional passa a manifestar-se na consciência individual que cada profissional desenvolve sobre o lugar e a posição que a sua profissão ocupa nas instituições sociais dominantes da sociedade. Esta formulação da identidade profissional, como posição e tomada de posição do lugar social e profissional ocupado, é salientada, em recentes revisões da literatura sobre identidade profissional em serviço social, como um dos principais traços da definição sociológica deste conceito (Webb, 2015; Roda e Fonseca, 2011).

O que temos em presença na passagem das formas identitárias comunitárias para as formas institucionais estatutárias - face à diversificação dos processos de socialização secundária e dos papéis e posições sociais que cada indivíduo contém na sua trajetória social (Mendes, 2001) - não será tanto uma dissociação autorreflexiva entre a identidade pessoal e a identidade social. Na visão que nos é dada por Claude Dubar (1997 [1991]) sobre a socialização profissional, tal como é assinalado, na figura 1, nas transições temporais que se identificam no cruzamento das dimensões $\mathrm{A}$ e $\mathrm{D}$, o que temos em presença é, potencialmente, a existência de um desencaixe nas trajetórias sociais dos indivíduos entre a identidade-para-si herdada, obtida na socialização primária, e a identidade-para-si veiculada pela socialização secundária. É este desencaixe socializador que faz com que os processos sociais de categorização da identidade herdada e da pertença social primária deixem de se ajustar espontaneamente à identidade-para-os-outros que ocorre - por via de uma escolaridade prolongada e na emergência da adultidade - com a entrada no mercado de trabalho, com o estabelecimento de vínculos contratuais com organizações económicas e com a antecipação dos novos grupos de referência (novos grupos de sociabilidade e de estilos de vida) a que se projeta/ambiciona vir a pertencer (significativamente diferentes daqueles a que pertenciam pela sua herança cultural).

Nesta linha de análise serão de sublinhar as formulações de Richard Jenkins (2000): a modernização dos processos de identificação social decorre principalmente de uma mudança dos contextos institucionais da identização. E é esta mudança que vai permitir o desenvolvimento, em novos termos, da reflexividade social e da consciência individual sobre os processos de identificação social na 
sociedade capitalista industrial, em contraponto à dissolução dos processos sociais comunitários de identização centrados apenas na reprodução automática do habitus na interação social (Caria, 2002). Mais especificamente, a consciência discursiva sobre a atividade profissional, como forma institucional, será tanto mais desenvolvida e partilhada quanto maior for o desencaixe socializador identitário, admitindo-se facilmente que os grupos sociais de origem e de socialização primária dos profissionais possam estar bastante aquém das disposições requeridas e das competências/poderes de que os mesmos necessitam para ao longo da sua trajetória social poderem competir e cooperar nos campos profissionais com outros grupos e identidades sociais e profissionais.

A consciência identitária individual-institucional poderá ser, hipoteticamente, mais facilmente desenvolvida quando no seu desenvolvimento é coletivizada, por via da sua partilha e negociação na interação social com os pares da profissão, dando lugar à existência, tal como já atrás referimos, de uma cultura profissional numa atividade institucional comum. Poderá também ser mitigada, durante algum tempo e para algumas atividades, na medida em que os profissionais consigam assegurar - por via do habitus e das eventuais equivalências e homologias de posições sociais entre os vários campos sociais e simbólicos que atravessam as suas trajetórias sociais ${ }^{2}$ - alguma linearidade, consistência e congruência biográfica. Em qualquer caso, os processos de socialização profissional tropeçarão sempre em novos desencaixes identitários entre o passado herdado e o futuro antecipado, que precisarão de convocar a consciência identitária institucional.

A fim de melhor entender esta consciência identitária, François Dubet (2002) salienta as características muito peculiares do modo como os processos de socialização ocorrem nas instituições sociais, denominando-a como programa institucional de socialização. A teoria social estrutural-funcionalista filiada em Talcott Parsons é, segundo este autor, um bom exemplo de como a sociologia conseguiu explicar e legitimar estas modalidades de socialização típicas das relações sociais da sociedade industrial. Segundo Dubet, esta socialização busca ativamente compatibilizar a consciência discursiva dos indivíduos com a criação de homogeneidade cultural, apesar das desigualdades de poder, posições e estatutos sociais que as instituições contêm.

Neste quadro, a socialização ocorre pela identificação de cada indivíduo com a missão e com a função que cada organização inscreve como finalidade institucional das relações sociais, sendo estas reproduzidas como um modelo idealizado de comportamento, capaz de gerar autocontrolo à distância sobre os indivíduos (e não controlo comportamental direto e pessoal como existia nas identidades comunitárias) e portanto disciplinamento da consciência individual. Inevitavelmente todos os comportamentos e formas de pensamento que se desviarem deste quadro institucional idealizado terão sanções sociais e juízos normativos que poderão ir até à exclusão da instituição, especialmente se as capacidades de autocontrolo não estiverem suficientemente evidenciadas.

2 Sobre os limites desta explicação e sua relação com os processos socializadores, filiada na teoria dos campos de Pierre Bourdieu, ver Lahire (2001). 
Estas identidades sociais institucionais-estatutárias-idealizadas foram promovidas ativamente pelos estados nacionais e, por esta via, tenderam a anular a força socializadora das identidades comunitárias e locais, gerando, segundo Kaufmann (2004), uma cada vez maior abstração da noção de indivíduo quanto mais a separação entre estado e sociedade civil se foi impondo como uma das forças estruturantes do capitalismo industrial. Saliente-se que estas identidades sociais são indissociáveis do aparecimento, consolidação e desenvolvimento dos movimentos e ideologias nacionais e nacionalistas a que Benedict Anderson (1991 [1983]) chama geração de comunidades imaginadas, por contraposição às culturas comunitárias de interconhecimento.

Neste quadro, em que as identidades sociais se confundem com o poder centralizado dos estados nacionais, a força centrífuga da identidade-para-outros deixa em grande medida de ser regulada pela interação social e passa a depender do que as instituições de trabalho, educação e conhecimento, socializadoras dos profissionais, projetam abstratamente querer/dever ser cada profissão (tal como é assinalado na "dimensão D" da figura 1). É aqui que a forma identitária estatutária mais se revela, pois a socialização e a identidade profissionais passam a conter uma visão projetada/imaginada e idealizada/virtual do que se pretende para a profissão, que não se circunscreve apenas ao presente atual e real da profissão (tal como é assinalado na figura 1, na diferenciação que se estabelece entre as dimensões C e D).

É neste âmbito que cabe às associações profissionais (eventualmente na forma jurídica de ordens profissionais, ou o seu equivalente legal conforme os países, quando se trata de profissões instituídas com poder delegado pelo estado) e às escolas de educação superior das profissões criar um perfil ideal de profissional, uma ideologia profissional, capaz de - para além de (in)formar - garantir, controlar e vigiar à distância a realização de um projeto de poder profissional. Passa a haver uma identidade-para-os-outros que tem e busca uma legitimidade de poder, uma identidade profissional legítima (tal como é assinalado na figura 1, a modalidade identitária BD), capaz de normativamente sancionar as consciências individuais menos conformadas à explicitação de um autocontrolo pessoal idealizado, incluindo a censura sobre a manifestação, na cultura profissional, de formas de ação e atitudes consideradas pouco legítimas.

Foi nesta forma identitária profissional, institucional-idealizada, que nos baseámos para o desenvolvimento do estudo empírico sobre os profissionais de serviço social, dado ser um formato identitário que depende, em parte, como vimos, da força socializadora das organizações de educação formal para orientar a ação dos assistentes sociais no contexto de trabalho, istoé, da consciência discursiva que cada profissional tem do poder legitimador do ensino-aprendizagem de obras e autores fundacionais desta área de conhecimento para conseguir ter justificações generalistas e racionalizações ético-deontológicas para as decisões e improvisos envolvidos nos contextos de ação profissional. 


\section{Atualidade da análise da consciência identitária institucional}

É claro que a história das formas sociais identitárias e dos processos socializadores a elas associados não acaba na sociedade industrial. Contemporaneamente, no quadro das sociedades capitalistas pós-industriais e da modernidade tardia, Claude Dubar (2000) fala-nos de outras duas formas identitárias: do individualismo narrativo-reflexivo e das formas culturais reflexivas de projeto. Em ambos os casos, elas ocorrem porque, segundo Dubet, neste novo período histórico de desenvolvimento do capitalismo o programa institucional de socialização começa a sofrer uma forte erosão, podendo daqui decorrer duas construções identitárias alternativas: (a) a componente social da consciência discursiva dilui-se ao ponto de as construções identitárias serem apenas o resultado de narrativas autorreflexivas (quase somente baseadas na força centrípeta das identidades pessoais), sem aspirações a produzir estabilidade, consistência e congruência social nos relatos biográficos; (b) a componente social da identidade é reforçada ao ponto de a consciência discursiva dos indivíduos procurar criar horizontes comuns de futuro coletivo nas organizações de trabalho (cultura de projeto associada, ou não, ao profissionalismo organizacional; Evetts, 2003; Webb, 2015), atualizando na interação social entre pares as culturas profissionais que anteriormente operavam apenas no quadro institucional. Tendencialmente, estas duas formas identitárias são complementares, pois ambas parecem contribuir para o surgimento de identidades sociais fragmentadas, flutuantes e situacionais, isto é, contribuir para a emergência do conceito, inspirado na obra de Erving Goffman, de identidades sociais múltiplas (Mendes, 2001), nas quais os desencaixes biográficos que ocorrem nas trajetórias sociais deixam de se constituir como objetos da consciência identitária.

No entanto, não é por o futuro da teoria social da identidade estar em aberto que deixamos de poder olhar para o passado e colocar a hipótese de saber (por via de um estudo empírico extensivo, por questionário) até que ponto o núcleo central dos processos socializadores institucionais da sociedade capitalista - que tem assegurado a continuidade da modernização das sociedades contra as forças identitárias comunitaristas e individualistas - persiste, resiste a adaptar-se, no presente, ao ponto de (continuar a) constituir o núcleo central da socialização profissional dos assistentes sociais, isto é, o essencial da consciência identitária (institucional e legítima) do serviço social.

Julgamos que esta hipótese tem particular atualidade se tomarmos em consideração algumas das especificidades do serviço social em Portugal e que tendem hoje a ser consideradas consensuais no projeto ideológico da profissão, a saber: (a) uma parte importante da socialização para a identidade social da profissão, realizada na educação formal superior, sempre esteve associada ao desenvolvimento de conteúdos de ensino de forte pendor político-histórico, que associam a profissão à emergência da questão social como problema da sociedade industrial, ao reforço dos estados-nação através do surgimento e desenvolvimento das instituições do estado social e, finalmente, à identificação da profissão com as políticas sociais públicas e com a crítica ao assistencialismo; (b) na última década, a socialização para a identidade social da profissão adquiriu um reconhecimento público-estatal 
acrescido, pois passou a ter o estatuto de área autónoma do conhecimento universitário (existência de graduações e pós-graduações universitárias em Serviço Social, sem que a licenciatura tivesse sido amputada de um estágio curricular integrado), e a acreditação e avaliação destes cursos deixou de ser entendida apenas como uma área de aplicação das ciências sociais (CS), mas também como uma área de investigação-ensino específica, na dependência de doutorados em Serviço Social e distinta de outras áreas de conhecimento das CS.

Em consequência deste acréscimo de poder simbólico e académico do serviço social os doutoramentos desta área começam a multiplicar-se, sendo de salientar quanto ao seu conteúdo uma orientação que tende a reforçar as componentes de identidade institucional, tal como as definimos anteriormente, a saber: (a) fazer coexistir a história da profissão com a história das instituições do estado social; (b) associar o conhecimento científico e profissional ministrado na educação formal com a evolução dos conteúdos das políticas sociais públicas em vigor em Portugal desde a década de 1980; (c) problematizar a identidade profissional dos assistentes sociais a partir dos quadros de pensamento da sociologia das profissões.

Para coroar esta estratégia político-ideológica da profissão, desde 1997 que a Associação dos Profissionais do Serviço Social (APSS) se tem multiplicado em tentativas para conseguir ser institucionalizada como ordem profissional. De facto, o último documento desta associação (APSS, 2015), que visava suportar esta reivindicação junto da Assembleia da República, é uma expressão eloquente do quanto e do como a identidade dos assistentes sociais é afirmada através de um discurso que a faz depender de uma socialização institucional, tal como já atrás referimos, a saber: (a) associação entre estado social e profissão, (b) associação do conteúdo das políticas sociais públicas à história da profissão, (c) associação entre a educação formal dos assistentes sociais e a garantia de qualidade e melhoria das políticas sociais públicas. Esta reivindicação não teve até ao momento sucesso político-parlamentar, mas não é por isso que não deixaremos de tirar a ilação de que os poderes legítimos desta profissão assumem uma identificação direta com o conjunto dos papéis e dos estatutos sociais que são atribuídos pelo estado social em Portugal às instituições públicas e particulares que prestam serviços de proteção social, de intervenção comunitária, cuidados assistenciais, capacitação social, etc.

A juntar ao insucesso que a reivindicação de uma ordem profissional tem tido junto da opinião pública e política, Francisco Branco (2009a, 2009b) refere que o poder simbólico e académico que o serviço social tem conseguido obter não tem sido convenientemente acompanhado por um acréscimo de poder económico e social face a uma crescente precariedade e desvalorização do trabalho dos assistentes sociais e a uma maior competição com outras profissões sociais em Portugal. Em consequência, este autor frisa a importância de se analisar o trabalho dos assistentes sociais também à escala micro e meso das organizações onde exercem, e de se conceber a identidade profissional no quadro das equipas multidisciplinares existentes, salientando para isso a importância de se ver o serviço social como parte de um sistema de profissões. No entanto, este autor, na linha das correntes weberianas da sociologia das profissões, parece ver a não obtenção do monopólio legal da atividade 
profissional (institucionalização de uma ordem profissional) e a sua inscrição em dinâmicas organizacionais como um sinal de continuado risco de desprofissionalização, capaz de comprometer os avanços adquiridos no plano simbólico e académico, atrás referidos (Caria, 2013; Caria e Pereira, 2016).

A este propósito serão de assinalar as contribuições do trabalho de investigação realizado pelo projeto Sartpro $^{3}$ (Caria e Pereira, 2014), pois esta pesquisa - ao invés da abordagem clássica, absolutamente comprometida com a construção social identitária-institucional - desenvolve-se numa análise crítica do profissionalismo, dado que este nunca é dissociado da sociologia das organizações (Caria, 2013; Caria e Pereira, 2016), problematizando por isso a debilidade do poder económico e social dos assistentes sociais como parte das transformações da gestão pública das políticas sociais e da cultura organizacional do capitalismo pós-industrial e de como, por hipótese, as profissões (velhas e novas do trabalho social) podem exercer poder nas organizações para serem, em parte, sujeitos coletivos implicados nas transformações históricas das organizações pós-burocráticas. Em consequência, na pesquisa do projeto Sartpro colocou-se a hipótese de o serviço social nas organizações e nas equipas de trabalho social poder ser apenas uma parte da construção identitária profissional do trabalho social, enquanto forma cultural reflexiva de um projeto de poder profissional no quadro de um sistema de profissões sociais (Caria et al., 2014) sem que, assim, se corra o risco de os processos legítimos de socialização institucional (como vimos, centrados atualmente no poder simbólico e académico da profissão) "isolarem corporativamente" os assistentes sociais das condições sócio-organizacionais que atualmente são predominantes no trabalho social em Portugal (Silva e Caria, 2013).

Em conclusão, no âmbito estrito das instituições sociais que suportam o poder simbólico e académico da profissão, parece ser pertinente colocar a hipótese de saber, através de um estudo empírico, até que ponto as formas identitárias institucionais-idealizadas tendem a ocupar um lugar central na consciência discursiva dos assistentes sociais. No entanto, não deixamos de admitir - fruto das mais recentes transformações da sociedade portuguesa e da implicação do profissionalismo com as lógicas organizacionais, associada a uma relativa debilidade do poder económico e social da profissão - que a socialização profissional pode estar a mudar ao ponto de depender mais de dinâmicas culturais, organizacionais e coletivas de culturas de equipas de trabalho (ver Silva, 2005, 2015), e não tanto dos processos de socialização institucional desenvolvidos pelas escolas de educação formal e pelas associações profissionais com poder neocorporativo.

\section{Orientações para o estudo por questionário}

Do exposto pensamos ter ficado claro que entendemos a identidade profissional do serviço social como a consciência discursiva que os assistentes sociais têm do uso

3 Projeto de investigação "Saberes, Autonomias e Reflexividade no Trabalho Profissional no Terceiro Sector", financiado em Portugal pela Fundação para a Ciência e a Tecnologia (PTDC/CS-SOC/098459/2008). 
que fazem do conhecimento formal-legítimo (princípios e valores abstratos, modelos e atitudes gerais para a ação) que, simultaneamente, os identifica com o trabalho social e os distingue de outras profissões sociais.

Inspirados na teoria geral dos campos sociais de Pierre Bourdieu (com Wacquant, 1992), acrescentaremos, tal como já tínhamos referido atrás, que a identidade profissional institucional é uma tomada de posição sobre a legitimidade do lugar social que os assistentes sociais entendem ocupar no espaço social especializado (campo-sistema de relações entre instituições e agentes sociais) do trabalho social, isto é, uma tomada de posição sobre o valor relativo que atribuem à sua educação formal e, ao mesmo tempo, o reconhecimento que dão a essa formalização do conhecimento para definir a sua identidade social no trabalho. Deste modo, estabelecemos uma equivalência lógica e teórica entre indivíduo-instituição, consciência-trabalho e identidade social-poder legítimo.

Nesta orientação, enquanto tomada de posição num campo-sistema de relações, a identidade profissional permite, simultaneamente, gerar consensos tácitos e explícitos internos ao grupo profissional (efeito de homogeneização institucional) e gerar disputas e divergências quanto à legitimidade do conhecimento formal que melhor define a profissão. Neste quadro, podemos admitir que um estudo empírico por questionário permitirá aferir até que ponto a frequência, mais ou menos elevada, de uso de um certo tipo de conhecimento, ou do reconhecimento de uma maior ou menor responsabilidade no uso de um certo tipo de conhecimento, corresponderá aos temas e dimensões de maior homogeneidade e legitimação da identidade profissional. Ao contrário, a identificação de uma menor frequência de uso de outros tipos de conhecimento corresponderá aos conteúdos da identidade profissional que mais estão em disputa e que, portanto, sobre os quais mais dúvidas se poderão levantar acerca da sua adesão às dinâmicas da atividade organizacional e contextual em trabalho social.

Em consequência desta orientação poderemos dizer que a identidade profissional é resultante das relações que a subjetividade dos assistentes sociais estabelece entre educação formal, profissionalização e atividades de trabalho social. Assim, admitimos estar próximos do modo como pesquisas de outros autores têm problematizado a identidade profissional dos assistentes sociais em Portugal, designadamente os trabalhos realizados por Berta Granja (2008), Isabel Passarinho (2012) e Ana Costa e Silva (2005). No entanto, estas afinidades são bastante limitadas porque, ao contrário destas autoras, ao utilizarmos no nosso estudo empírico apenas um inquérito por questionário, problematizámos a consciência identitária sem analisar a consciência reflexiva que estes profissionais têm das suas trajetórias biográficas e/ou dos sistemas de trabalho de equipa e de organização em que se integram.

Comparativamente com estes estudos, o inquérito por questionário tem a desvantagem de abordar os indivíduos de uma forma atomizada, sem que haja qualquer outro elemento de análise contextual que permita validar a orientação simbólico-prática dada na resposta ao inquérito. Tem ainda o risco de ser vista apenas como uma atividade instrumental tão-só destinada a ser aplicada (ou a avaliar sobre a aplicação dos conhecimentos e competências) no terreno pelos 
práticos-profissionais (Branco, 2008). Mas, por outro lado, tem a vantagem de permitir caracterizar e medir o conteúdo (princípios e valores abstratos, modelos e atitudes para a ação) da identidade profissional a partir de um contexto de inquirição que condiciona e restringe o assistente social a autodefinir-se por relação direta e unilateral para com quem formulou o inquérito. No caso do nosso estudo, a universidade, com todo o seu poder simbólico e institucional para em grande medida definir o que é legítimo, ou não, dizer-se sobre o que é a identidade da profissão.

Mais especificamente, no nosso estudo utilizámos como instrumento de recolha de dados um questionário autoadministrado (com recolha e entrega do formulário de modo pessoal, sem haver qualquer relação de entrevista) e completamente estruturado (com perguntas fechadas que seguiam uma ordem fixa de temas e de perguntas).

Nestas condições, com esta elevada estrturação e diretividade no processo de inquirição, percebe-se que a consciência identitária que os assistentes sociais têm da especificidade da sua responsabilidade no trabalho social não será apenas o resultado da consciência discursiva sobre o uso do conhecimento aprendido (dimensão de análise que temos designado como recontextualização profissional do conhecimento em estudos que realizámos no passado sobre o trabalho e o saber profissional - Caria, 2008, 2011). Será mais a consciência da legitimidade do conhecimento que lhes foi inculcado na educação formal como devendo/podendo identificar o serviço social. Deste modo, podemos dizer que o questionário permite aferir melhor o discurso legítimo da profissão, isto é, uma aproximação mais fiel à consciência identitária institucional, do que outros contextos de inquirição. Tem, ainda, a possibilidade de ser visto como um instrumento reflexivo dos educadores e dos investigadores em serviço social, para estes poderem avaliar o seu trabalho de educação formal na medida em que percebem até que ponto o discurso legítimo da profissão está, ou não, suficientemente inscrito na identidade profissional realizada em serviço social.

Assim, o estudo realizado por nós tem mais afinidades com a pesquisa realizada, em 2011, por Rute Roda e Maria de Lurdes Fonseca (já referenciado atrás), também realizado por questionário sobre conteúdos específicos da identidade profissional em serviço social. No entanto, também aqui existem importantes diferenças, pois, ao contrário da pesquisa destas autoras, o nosso processo de inquérito não tem por base uma amostra comparativa de estudantes e de profissionais de serviço social, mas apenas uma amostra de profissionais que realizavam trabalho social em contextos de atividade variados no norte de Portugal.

Em conclusão, a definição operacional de que partimos para o nosso estudo por questionário considerou que a identidade profissional institucional do serviço social é a consciência individual que os assistentes sociais têm da legitimidade do conhecimento formal para definir a atividade da profissão no quadro do sistema de relações sociais que atualmente inscrevem o poder simbólico das instituições de trabalho social em Portugal.

O modo como esta definição foi operacionalizada em conteúdos temáticos e dimensões de análise sobre a identidade dos assistentes sociais e os resultados do consequente questionário serão objeto de análise noutro artigo. 


\section{Referências bibliográficas}

Anderson, Benedict (1991 [1983]), Comunidades Imaginadas. Reflexões sobre a Origem e a Expansão do Nacionalismo, Lisboa, Edições 70.

APSS - Associação dos Profissionais de Serviço Social (2015), "Pertinência da criação da Ordem dos Assistentes Sociais", consultado em 8 de fevereiro de 2016 no endereço eletrónico: http://www.apross.pt/quest\%C3\%B5es-profissionais/ordem-dos-assistentes-sociais/

Asquith, Stewart, Chris Clark, e Lorraine Waterhouse (2005), The Role of the Social Worker in the $21^{\text {st }}$ Century. A Literature Review, Edimburgo, Scottish Executive.

Bourdieu, Pierre (1972), Esquisse d'Une Théorie de la Pratique. Précédé de Trois Etudes d'Ethnologie Kabyle, Paris e Genebra, Droz.

Bourdieu, Pierre, e Loïc Wacquant (1992), Réponses. Pour Une Anthropologie Reflexive, Paris, Seuil.

Branco, Francisco (2008), “A investigação em Serviço Social em Portugal: trajectórias e perspectivas", Locus Social, 1, pp. 48-63.

Branco, Francisco (2009a), "Assistentes sociais e profissões sociais em Portugal: notas sobre um itinerário de pesquisas", Locus Social, 2, pp. 7-19.

Branco, Francisco (2009b), "A profissão de assistente social em Portugal”, Locus Social, 3, pp. 61-89.

Brown, Alan, Simone R. Kirpal, e Felix Rauner (orgs.) (2007), Identities at Work, Dordrecht, Springer Science \& Business Media.

Canavan, Martin (2009), "Professional identity formation and voluntary sector social work: messages from an evaluation of a 'flexible learning' programme in Northern Ireland", Journal of Practice Teaching E Learning, 9 (3), pp. 47-71.

Caria, Telmo H. (2002), “Da estrutura prática à conjuntura interactiva - relendo o esboço de uma teoria da prática de Pierre Bourdieu", Revista Crítica de Ciências Sociais, 64, pp. 135-143.

Caria, Telmo H. (org.) (2005), Saber Profissional, Coimbra, Almedina.

Caria, Telmo H. (2008), “O uso do conceito de cultura na investigação sobre profissões”, Análise Social, XLIII (189), pp. 749-773.

Caria, Telmo H. (2009), “Notas para uma perspectivação do trabalho técnico-intelectual como cultura profissional", em Telmo H. Caria, Carlos Gonçalves e Ana Paula Marques (orgs.) História, Trabalho e Conhecimento nas Profissões - Actas do I Colóquio Internacional sobre Grupos Profissionais / X Seminário ASPTI - Análise Social do Saber Profissional em Trabalho Técnico-Intelectual, Porto, Livpsi, XXVI-XXXIV.

Caria, Telmo H. (2011), “Perspectivar a intervenção social: reflexões e dados sobre o trabalho profissional e o uso do método etnográfico no terceiro sector", em José Portela, Octávio Sacramento e Pedro Silva (orgs.), Etnografia e Intervenção Social, Lisboa, Colibri, pp. 271-296.

Caria, Telmo H. (2013), “O trabalho profissional burocrático: modelo de análise sobre a profissionalização do trabalho social em organizações do setor não lucrativo em Portugal", Dados - Revista de Ciências Sociais, 56 (4), pp. 803-839.

Caria, Telmo H. (2014), “Hierarquias de conhecimento e saber profissional”, Cadernos de Pesquisa, 44 (154), pp. 798-826. 
Caria, Telmo H., Armando Loureiro, Isabel Costa, Fernando Pereira, e Filipa César (2014), “O sistema de profissões no trabalho social: trabalho de equipa, formação e jurisdições profissionais", em Telmo H. Caria e Fernando A. Pereira (orgs.), O Trabalho Social Profissional no Terceiro Setor, Viseu, PsicoSoma, pp. 171-201.

Caria, Telmo H., e Fernando Pereira (orgs.) (2014), O Trabalho Social no Terceiro Setor, Viseu, PsicoSoma.

Caria, Telmo H., e Fernando Pereira (2016), “Social work like a bureaucratic professional labour: an empirical analysis in non-profit organizations in Northern Portugal", European Journal of Social Work, 19 (1), pp. 120-139.

Champy, Florent (2011), Nouvelle Théorie Sociologique des Professions, Paris, Presses Universitaires de France.

Dubar, Claude (1996), "Usages sociaux et sociologiques de la notion d'identité", Education Permanente, 128, pp. 37-44.

Dubar, Claude (1997 [1991]), A Socialização. A Construção das Identidades Sociais e Profissionais, Porto, Porto Editora.

Dubar, Claude (2000), La Crise des Identités. L'Interprétation d'Une Mutation, Paris, Presses Universitaires de France.

Dubet, François (2002), Le Déclin de l'Institution, Paris, Seuil.

Evetts, Julia (2003), “The sociological analysis of professionalism occupational change in the Modern World", International Sociology, 18 (2), pp. 395-415.

Freidson, Eliot (1994), Professionalism Reborn, Cambridge, Polity Press.

Giddens, Anthony (1994 [1991]), Modernidade e Identidade Pessoal, Oeiras, Celta Editora.

Granja, Berta (2008), Assistente Social. Identidade e Saber, Porto, Universidade do Porto, tese de doutoramento.

Hall, Stuart (2002 [1992]), A Identidade Cultural na Pós-Modernidade, Rio de Janeiro, DP\&A (7. ․ㅡ edição).

Jenkins, Richard (2000), "Categorization: identity social process and epistemology", Current Sociology, 48, pp. 7-25.

Kaufmann, Jean-Claude (2004), L'Invention de Soi. Une Théorie de l'Identité, Paris, Armand Colin. Lahire, Bernard (2001), Le Travail Sociologique de Pierre Bourdieu, Paris, La Découvertte \& Syros.

Madureira-Pinto, José (1991), “Considerações sobre a produção social de identidade”, Cadernos de Ciências Sociais, 32, pp. 217-231.

Mendes, José Manuel (2001), “O desafio das identidades”, em Boaventura de Sousa Santos (org.), Globalização. Fatalidade ou Utopia, Porto, Afrontamento, pp. 489-523.

Monteiro, Maria B., Maria L. Lima, e Jorge Vala (1999), “Identidade social: um conceito-chave ou uma panaceia universal?", Sociologia, Problemas e Práticas, 9, pp. 107-120.

Passarinho, Isabel Cristina (2012), As Formigas e os Carreiros. Uma Abordagem de Inspiração Biográfica aos Percursos de Aprendizagem e à Construção Identitária de Assistentes Sociais, Lisboa, Instituto de Educação da Universidade de Lisboa, tese de doutoramento.

Payne, Malcolm (2006), “Identity politics in multiprofessional teams palliative care Social Work", Journal of Social Work, 6 (2), pp. 137-150. 
Roda, Rute, e Maria de Lurdes Fonseca (2011), “A qualidade e a persistência das aquisições identitárias dos assistentes sociais em Portugal", Intervenção Social, 38, pp. 147-184.

Sainsaulieu, Renaud (1977), Identité au Travail. Les Effets Culturels de l'Organisation, Paris, Presses de la Fondation Nationale de Sciences Politiques.

Santos, Clara C. (2005), "A construção social do conceito de identidade profissional", Interacções, 8, pp. 123-144.

Silva, Ana Maria Costa e (2005), Formação e Construção de Identidade(s). Um Estudo de Caso Centrado Numa Equipa Multidisciplinar, Braga, Universidade do Minho, tese de doutoramento.

Silva, Ana Maria Costa (2015), Assistentes Sociais e Mediadores. Construindo Identidades Profissionais, Lisboa, Chiado Editora.

Silva, Margarida, e Telmo Caria (2013), “Para além da 'desprofissionalização': que futuro para o saber profissional em trabalho social e em organizações neoburocráticas?", em Telmo H. Caria, Vera Fartes e Amélia Lopes (orgs.), Saber e Formação no Trabalho Profissional de Relação, Salvador da Bahia, Editora da Universidade Federal da Bahia, pp. 61-80.

Sousa, Paula (2014), Experiência e Lógicas de Ação no Serviço Social, Lisboa, Universidade Católica Portuguesa, tese de doutoramento.

Webb, Stephen (2015), "Professional identity and social work", consultado em 8 de fevereiro de 2016 no endereço eletrónico: https://gcal.academia.edu/StephenWebb

Telmo H. Caria. Docente de Sociologia, Antropologia e Ciências Sociais da Universidade de Trás-os-Montes e Alto Douro (UTAD, Portugal) e investigador em Etnografias do Saber Profissional no Centro de Estudos Transdisciplinares em Desenvolvimento (Cetrad) da UTAD, no Centro em Rede de Investigação em Antropologia (CRIA, Portugal) e no Centro de Intervenção e Investigação em Educação (CIIE) da Faculdade de Psicologia e Ciências da Educação da Universidade do Porto (UP, Portugal). E-mail: tcaria@utad.pt

Paula Sousa. Doutorada em Serviço Social, docente de Serviço Social da Universidade de Trás-os-Montes e Alto Douro (UTAD, Portugal) e investigadora do Centro de Estudos Transdisciplinares em Desenvolvimento (Cetrad) da UTAD. E-mail: paulasousa@utad.pt

José Luís Almeida. Diretor da licenciatura em Serviço Social e docente de Serviço Social da Universidade de Trás-os-Montes e Alto Douro (UTAD, Portugal) e investigador do Centro de Estudos Transdisciplinares em Desenvolvimento (Cetrad) da UTAD. E-mail: joseluis@utad.pt

Receção: 17 de abril de 2016 Aprovação: 13 de fevereiro de 2017 
